\title{
Pollution Characteristics of Typical Antibiotic Resistance Genes in Sludge Treatment Wetlands
}

\author{
Zhuma L uosang ${ }^{1,2}$, Wanjun Zhang ${ }^{1,2, *}$, Junwen $\mathrm{M} \mathrm{a}^{1}$, fengying Huang ${ }^{1,2}$, and Yubo Cui ${ }^{1,2}$ \\ ${ }^{1} \mathrm{~K}$ ey Laboratory of Biotechnology and Bioresources Utilization, M inistry of Education, Dalian M inzu U niversity, Dalian 116600, China \\ ${ }^{2}$ College of Environment and Resources, Dalian M inzu University, Dalian 116600, China
}

\begin{abstract}
The in-situ static box method was used to conduct a comparative experiment on sludge treatment wetlands (STW S). STW 1 had ventilation structure, without reeds and STW 2 had ventilation and was planted with reeds. The absolute abundance of sulfonamide, tetracycline and macrolide antibiotic resistance genes (ARGs) in the two STWs were analyzed, and the paper discussed pollution characteristics of typical antibiotic resistance genes in the two STW s. The results showed that three ARGs, sul 1 (sulfonamides), tetC (tetracyclines), ermf (macrolides), were detected in STW 1 and STW 2. The concentration of arginine was sul $1>$ tetC > ermf. The concentration level of AGRS in STW 1 and STW 2 was lower in bottom layer than that of surface layer sludge. The removal efficiency of ARGs in the same system was tetC > sul $1>$ ermf, and the removal efficiency of surface sludge and bottom sludge in different systems was STW $2>$ STW 1 . Planting wetland plants in the STW can promote the removal of ARGs.
\end{abstract}

\section{Introduction}

As a new type of pollutant, antibiotic resistance genes (ARGs) is persistent in environmental media, and can be transferred and transmitted among different bacterial populations through gene level transfer ${ }^{[1]}$. The development and spread of microbial drug resistance will be an important public-health issue. Although the pollution sources of ARGs are diversified and complex, one of the main reasons for its rapid spread in the environment is the antibiotic residues of man-made wastes. The resistance selection pressure of manure agriculture to soil microorganisms and horizontal gene transfer make the diffusion and transfer of resistance genes continue ${ }^{[2]}$. Human production and life style have changed the distribution and concentration of resistance genes in sediment, soil and other environmental media [3,4]. The main sources and pathways of resistance genes in soil environment are shown in Fig.1. The wastewater from medical treatment, industry, aquaculture and daily life is the main medium for the transmission of resistance genes in the environment. Some resistance genes enter the sewage treatment plant in the form of parent or metabolites and transfer to the soil environment with the way of sludge farming, and some are directly discharged into the environment. Even if the resistant bacteria can be effectively killed and wiped out, when the DNA released into the environment combines with humus and other substances, it will escape the vicious circle of accounting enzyme degradation and cause resistance gene pollution ${ }^{[5]}$. The removal of resistance genes in existing sludge treatment processes and sewage treatment technologies is limited, and the vast majority of resistance genes enter the soil environment through agricultural utilization, thus causing pollution to plants. A large number of resistance genes in the environment pose a threat to human health through enrichment and amplification of the food chain.

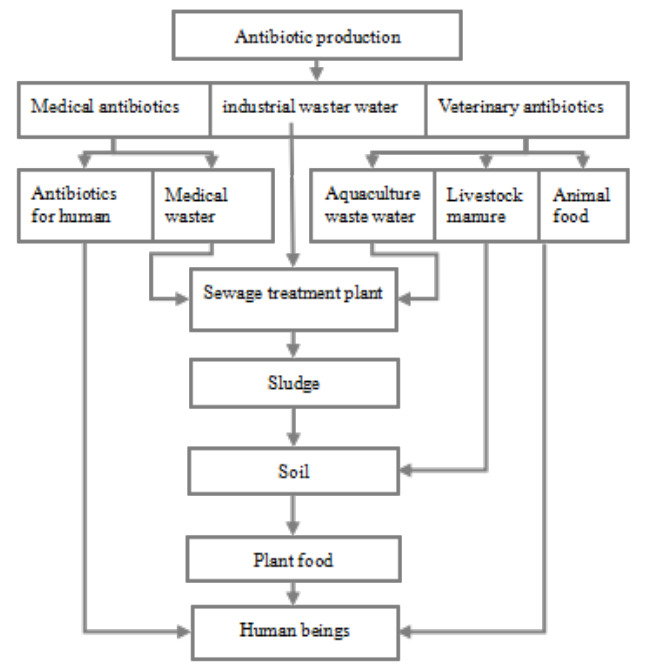

Fig.1.Transmission of antibiotic resistance genes in soil

Sludge treatment wetlands (STWs) is a kind of sludge resource utilization technology which uses constructed wetland to dewater and stabilize the excess sludge of urban sewage treatment plant ${ }^{[6]}$. STWs has the advan of low investment is without chemical agent, and the final product after treatment can be used in agriculture ${ }^{[7]}$. In this study, fluorescence quantitative PCR was used to determine the distribution and variation

\footnotetext{
* Corresponding author: zhangwanjun@ dlnu.edu.cn
} 
of typical resistance genes in different systems in sludge treatment wetlands. The distribution differences of resistance genes in different sludge treatment wetlands analysis, and the dynamic succession law of resistance gene distribution with time and environmental factors in sludge treatment wetlands was explored. Further strengthen the understanding of the mechanism, design, optimization and management of STWs, provide a scientific basis for the establishment of resistance gene safety evaluation and early warning system in soil ecological environment, and have important theoretical and practical significance in ecological environment protection and human health protection.

\section{Materials and methods}

\subsection{Wetlands system and sampling}

The current research system was located in the Dakai WWTP, Dalian, China, and the remaining sludge after the sewage treatment by the activated sludge method was stabilized. The treatment line consists of two sludge pumps, a cloth sludge distribution tank as pretreatment, three vertical subsurface flow (VF) constructed wetlands $(3.0 \mathrm{~m} \times 1.0 \mathrm{~m} \times 1.3 \mathrm{~m}(\mathrm{~L} \times \mathrm{B} \times \mathrm{H}))$ in parallel, and finally drainage system. Except for the basement layer, the three systems were totally different in structure (only STW1 and STW2 were analyzed in this study); STW 1 and STW 2 had ventilation structure, and STW 2 and STW 3 waS planted with reeds.

The sampling time was from April to November, evenly distributed in spring, summer, autumn and winter. The sludge of STW1, STW2 and bottom sludge were collected and mixed to reduce the error of single sampling. The sludge samples were stored in a lowtemperature ice box and transferred to the laboratory for ARGs detection at $-80{ }^{\circ} \mathrm{C}$.

\subsection{Antibiotic resistance genes detection}

The genomic DNA of sludge samples was extracted by FastDNA ${ }^{\circledR}$ Soil Rotation Kit, and the concentration and content of DNA were measured by gel electrophoresis and spectrophotometer. The absolute abundance of sulfonamides resistance genes, tetracyclines resistance genes and macrolide resistance genes (sul1, tetC, ermf) was determined by qPCR.

\section{Results and discussion}

\subsection{Distribution of three antibiotic resistance genes in sludge treated wetlands}

In order to study the pollution characteristics of ARGs in STWs, we analyzed the absolute abundance of three ARGs (sul1, tetC, ermf) during sludge stabilization in the resting period in STWs, as shown in Fig.2. Generally, three kinds of ARGs were detected in STW 1, STW 2 surface sludge and bottom sludge, among the ARGs, sull showed the highest concentrations, followed by tetC, and the abundance of ermF was lower in two STWs. This is consistent with previous research results. Ma et al. Analyzed that the concentration of sull is the highest among ARGs in sludge stabilization period 5, followed by tetC, sul2, TetA and ermB ${ }^{[8]}$.

According to the results of Fig.2., the absolute abundance of ARGs in surface sludge was higher than that in bottom sludge at the same period in STW1 and STW2. It may be that although the ventilation pipe was set up, the oxygen content in the bottom sludge was always lower than that in the surface sludge, and the hypoxia environment prevents the growth of some bacteria, thus promoting the reduction of ARGs.This is consistent with the study that Miller et al. Anaerobic environment can reduce the abundance of resistance genes to a certain extent ${ }^{[9]}$. In both STW1 and STW2, ARGs decreased the most from June to September, which was due to the higher system temperature in summer, and consistent with previous studies. High temperature can promote the removal of ARGs ${ }^{[10]}$.
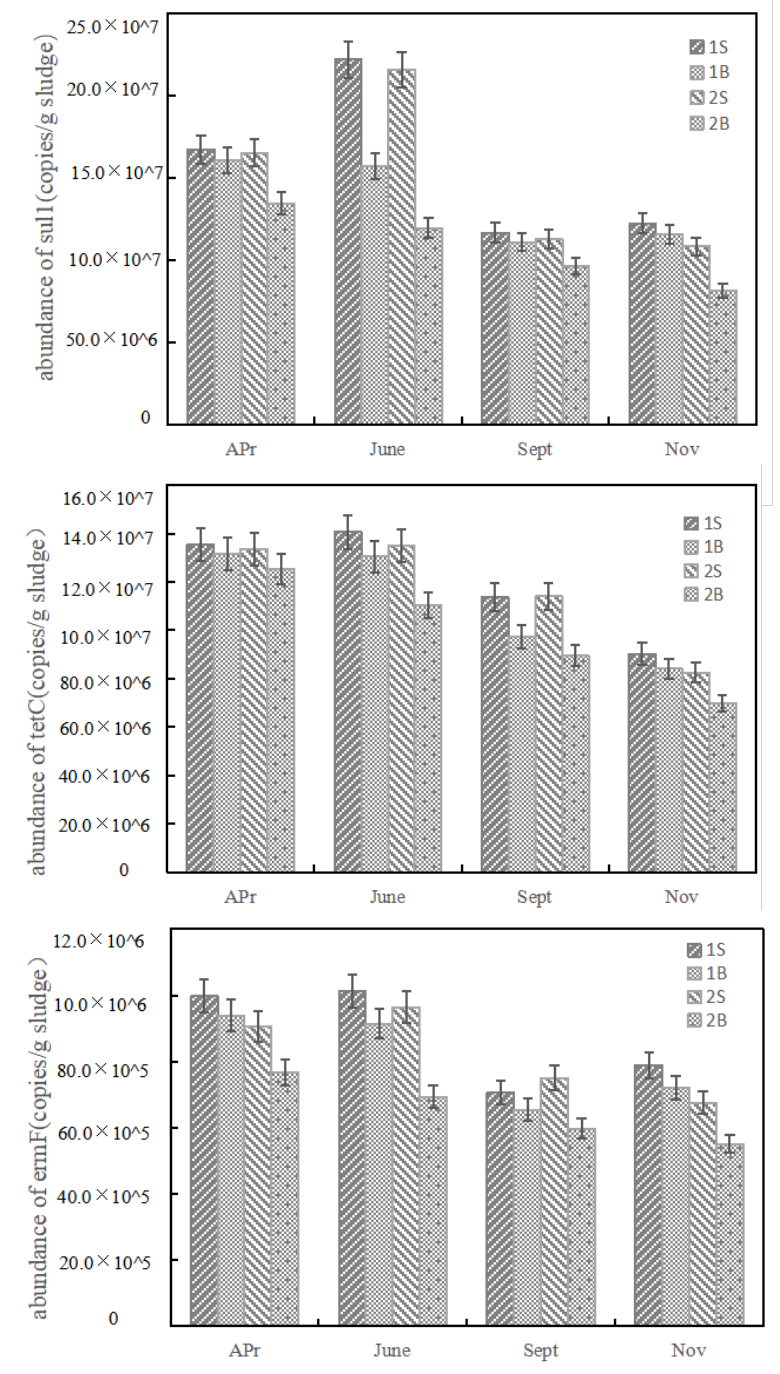

Fig.2. Changes of sul1, tetC and ermF ARGs in two STWs

The highest values of the three ARGs appeared in the surface sludge were $22.2 \times 10^{\wedge} 7$ copies $/ \mathrm{g}, 14.1 \times 10^{\wedge}$ 7 copies / g, $10.1 \times 10^{\wedge} 6$ copies $/ \mathrm{g}$ (sul1, tetC, ermF).If 
ARGs in excess sludge is not reduced and removed, ARGs will be enriched in excess sludge and brought into soil and other environment with sludge resource utilization.

\subsection{Removal efficiency of three antibiotic resistant genes in sludge treated wetlands}

In this study, three kinds of ARGs in the two sludge treatment wetlands decreased significantly, indicating that the sludge treatment wetlands can effectively remove ARGs from the excess sludge of the sewage treatment plant. This is consistent with the fact that Wang and Shi can reduce the resistance genes of macrolides and quinolones in wetlands treated with sludge ${ }^{[11,12]}$. The removal rates of three kinds of ARGs (sul1, tetC, ermF) in STW1 and STW2 in the stable period of one year are shown in Fig.3. In the surface and bottom sludge of STW1 and STW2, the removal rate of tetracycline resistance gene (tetC) was the highest, followed by sulfonamide resistance gene (sul1) to macrolide resistance gene (ermF) was the lowest.

This is similar to Cristina et al's study on the removal of antagonistic genes in two vertical flow wetlands, which showed that the average removal rates of sul2 and ermB are $33-97 \%$ and $9-99 \%$ respectively ${ }^{[13]}$. STW2 has a high removal rate of STW 1 to three kinds of $A R G S$ (sul1, tetC, ermf) in surface sludge and bottom sludge. This reason was that STW 2 planted wetland plants, and reed can actively absorb ARGs in sludge. V accag $G$ et al. It has been verified that plant roots can absorb and retain microorganisms in sludge to a certain extent, thereby reducing the number of microorganisms in stabilized sludge and effectively reducing ARGs in stabilized sludge ${ }^{[14]}$. Zhang et al. analyzed the microbial DGGE profile diversity in STW2 sludge samples and found that the microbial diversity in Reed was higher than that in sludge ${ }^{[15]}$. In addition, Wang et al used Illumina-MiSeq sequencing technology to analyze the STWs microbial community. The results showed that the plant growth in STWs could promote the diversity and richness of bacteria, and improve the removal rate of organic matter and nutrients in the system ${ }^{[16]}$.

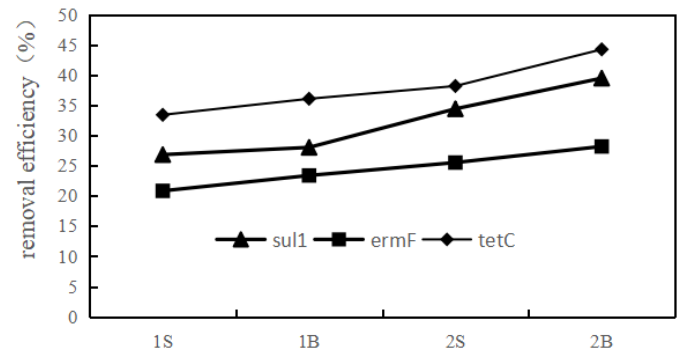

Fig.3.Removal efficiency of sul1, tetC and ermF ARGs in two STWs

In conclusion, STWs has a significant removal effect on three kinds of ARGs: sull (sulfonamides), tetC (tetracyclines) and ermF (macrolides), and planting wetland plants can remove ARGs in the excess sludge of sewage treatment plants more effectively. In this paper, the pollution characteristics of resistance genes in stable period were explored, and the distribution and removal of resistance genes in load period shoud be studied in the future.

\section{Conclusions}

By comparing the pollution characteristics of three typical resistance genes of STW1 and STW2 in different periods, it was found that the concentration of arginine of sul1, tetC and ermF; in STWs was sul1 > tetC > ermF, ARGs in STW1 and STW2, and the enrichment degree of sul1, tetC and ermF; in surface sludge was higher than that in bottom sludge. In the same system, the removal rates of three kinds of ARGs are tetC $>$ sull $>$ ermF. In different systems, the removal rate of ARGs is the highest in the bottom sludge of STW2, followed by the surface sludge of STW2 and the bottom sludge of STW1, and the removal rate of surface sludge of STW1 is the lowest, that is, the removal rate of both surface sludge and bottom sludge is STW1 < STW2. Therefore, in SWTs, planting wetland plant Reed can promote the reduction of resistance genes in the process of sludge stabilization.

\section{Acknowledgements}

The research was financed by the Science and Technology Innovation Foundation of Dalian, China (2018J12SN080) and Natural Science Foundation (National Innovation Joint Fund) of Liaoning, China.

\section{References}

1. B.J XU, Y. LUO, Q. ZHOU, et al. J ournal of Enviro nmental Science, Antibiotic resistance gene: a new e nvironmental pollutant, 28, 1499-1505, (2019)

2. X.X. YUAN, J.Y. LIANG, L.X. FAN, et al. Acta Pedologica Sinica, Effects of Manure Application on Source and Transport of Antibiotic Resistant Genes in Soil and Their Affecting Factors, 57,36-47, (2020)

3. H.E. HOLGER, S.L.H.T. QODIAH, Z.M.L. UTE, et al. Environ. Microbiol, Accumulation of sulphonamide resistance genes in arable soils due to repeated application of manure containing sulfadiazine, 77,2527-(2530)

4. P.R.D. AMY, P. RUOTING, S.T.B. HEATHER, et al., Environmental Science \& Technology, Antibiotic resistance genes as emerging contaminants: studies in northern Colorado, 40,7445-7450(2006)

5. J. XU, P. HU, J.P. LU, et al., Science \& Technology Review, Characteristics and control measures of antibiotic and resistance gene pollution in water environment, 36,13-23(2018)

6. Y.B. CUI, Z.Q. GUO, Y.H. LIU, et al. Journal of Chongqing Jianzhu University, Study on ecological stabilization of excess sludge, 33,151-156(2011) 
7. Y.B. CUI, Journal of Jilin Agricultural University, Research progress of sludge treatment technology in Constructed Wetland, 39,1-9(2017)

8. J.W. MA, Y.B. CUI, A.M. LI, et al. Science of the total environment, Evaluation of the fate of nutrients, antibiotics, and antibiotic resistance genes in sludge treatment wetlands, 712,13-63+70(2020)

9. J.H. MILLER, J.T. NOVAK, W.R. KNOCKE, et al. Water Environment Research A Research Publication of the Water Environment Federation, Effect of silver nanoparticles and antibiotics on antibiotic resistance genes in anaerobic digestion, $\mathbf{8 5 , 4 1 1 ( 2 0 1 3 )}$

10. P. WEI, F.Y. HUANG, J.Q. SU, et al. Journal of Environmental Engineering, Effects of composting on tetracycline antibiotics and resistance genes in sludge, 8,5431-5438 (2014)

11. C. WANG, Dalian University of Technology, Removal Efficiency and Correlation Study of Antibiotics and Related Resistance Genes in Sludge Drying Reed Beds (2018)

12. S.F. LI, Dalian Minzu University, Study on Removal Efficiency of Quinolone Antibiotics and Resistance Genes in Sludge Treatment of Wetland Stabilized Sludge (2020)

13. A. CRISTINA, J. MARAIA, G. GALAN, et al. J ournal of Hazardous M aterials, New insights on the combined removal of antibiotics and ARG inurban wastewater through the use of two configurations $f$ verticalsubsurface flow constructed wetlands, 03,163(2020)

14. G. VACCA, H. WAND, M. NIKOLAUSE, et al., W ater Research, Effect of plants and filter materials on bacteria removalin pilot-scale constructed wetlands, 39, 1361(2005)

15. W.J. ZHANG, Y.B. CUI, Y. WANG, et al. J ournal of safety and environment, Study on the diversity of Endophytes in reed bed with sludge drying, 17,1407-1412(2017)

16. S.Q. WANG, Y.B. CUI, A.M. LI, et al. Journal of Environmental $M$ anagement, Deciphering of organic matter and nutrient removal and bacterial community in three sludge treatment wetlands under different operating conditions, 260,11-01+59(2020) 